\title{
PENERAPAN SIFAT QANAAH DALAM MENGENDALIKAN HAWA NAFSU DUNIAWI
}

\author{
Alwazir Abdusshomad \\ Dosen Politeknik Penerbangan Indonesia Curug \\ alwazir85@gmail.com
}

\begin{abstract}
Abstrak
Sesungguhnya Hawa nafsu merupakan salah satu faktor yang menghalagi seseorang dari beribadah kepada Allah SWT dan menjauhkannya dari ketaatan kepada-Nya, serta menjerumuskannya ke dalam kubangan dosa dan kenistaan. Seseorang harus melawan nafsunya dari hal-hal yang dapat mendatangkan murka Allah SWT. Maka dari itu manusia terbagi menjadi dua kelompok, pertama, manusia yang dikalahkan dan dikuasai oleh hawa nafsunya, Ia benar-benar tunduk dibawah perintah dan kendalinya dan yang kedua adalah manusia yang berhasil memenangkan pertarungan melawan hawa nafsunya, Ia mampu mengendalikanya, menundukkannya, dan hawa nafsu pun tunduk dibawah perintah dan kendalinya. Salah satu cara agar tidak menjadi kendali hawa nafsu duniawi adalah dengan penerapan sifat Qana'ah, yaitu orang yang merasa puas dengan apa yang telah ia miliki, dan menerima apapun anugerah yang telah diberikan oleh Allah kepadanya, baik banyak ataupun sedikit, sehingga ketika sifat Qona'ah bisa diterapkan pada diri manusia niscaya hawa nafsu rakus, serakah dan perilaku tercela lainya akan dapat dihindari.
\end{abstract}

Kata Kunci : Penerapan Qona'ah, Pengendalian, Hawa Nafsu Duniawi

\section{Abstrack}

Indeed, your desires is a factor that barring someone to pray toward Allah SWT and keeps away from His rules. It also drives human to do immoral and oversight things. Someone must have come up against their own desires that can be shown His anger. That's why, human can be categorized as two grups; the first, persons were defeated and controlled by their desire. They were exactly controlld by his ambition. The second, persons won the fight against their own desires. They were able to control and beat them. Otherwise, their desires can be handled by themselves. The way to avoid the material desires is by practicing the Qanaah. Qanaah is the feeling of satisfaction with the blessing Allah SWT, whatever size and amount they got. Practicing Qanaah can be applied in the daily life so that bad behavior of human being can be avoided.

Keywords : Practicing Qanaah, controlling, material desires 


\section{Jurnal Asy-Syukriyyah}

\section{A. PENDAhUluan}

Allah menciptakan manusia dengan kesempurnaan dan keunikan . hal ini dilihat dari segala hal yang menyangkut fisik dan jiwa seorang manusia. Ia berbeda dengan makhluk lainnya dan bahkan Allah memerintahkan malaikat untuk bersujud kepada Adam AS karena akal, pengetahuan dan hawa nafsu yang dianugerahkan kepadanya. Sebagaimana firman Allah SWT dalam surat At Tin berikut ini :

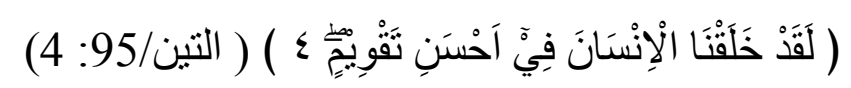

Artinya : "Sungguh, Kami telah menciptakan manusia dalam bentuk yang sebaikbaiknya." (At-Tin/95:4)

Sejak awal penciptaannya, manusia pertama yakni Adam AS telah mengakui Allah sebagai Tuhannya dan hal tersebut mendorong manusia untuk senantiasa beriman kepada Allah SWT. Penciptaan manusia juga memiliki hakikat bahwa Allah menciptakan agama Islam sebagai pedoman hidup yang harus dijalani oleh manusia selama hidupnya. Seluruh ajaran Islam adalah diperuntukkan untuk manusia dan oleh karena itu manusia wajib beriman dan bertaqwa kepada Tuhan yang maha esa yakni Allah SWT. Adapun Allah menciptakan manusia untuk mengabdi dan menjadi hamba yang senantiasa beribadah dan menyembah Allah SWT sebagaimana yang disebutkan dalam ayat berikut :

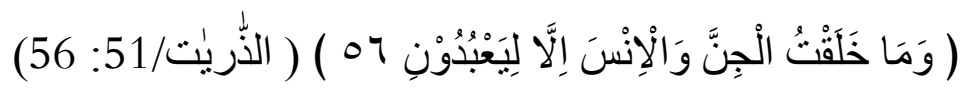

Artinya : "Aku tidak menciptakan jin dan manusia melainkan agar mereka beribadah kepada-Ku.” (Az-Zariyat/51:56)

Selain diciptakan menjadi hamba Allah, manusia juga diciptakan sebagai khalifah. Kata khalifah sendiri berasal dari bahasa arab yakni khalafa atau khalifatan yang artinya meneruskan, sehingga kata khalifah yang dimaksud adalah penerus agama Islam dan ajaran dari Allah SWT. Sebagai manusia yang berperan sebagai khalifah maka 


\section{Jurnal Asy-Syukriyyah}

manusia wajib menjalankan tugasnya untuk senantiasa menjaga bumi dan makhluk lainnya dan ia akan dimintai pertanggungjawaban atas apa yang diperbuatnya kelak di hari akhir. Hal ini disebutkan dalam firman Allah SWT Surat Al baqarah ayat 30 yang bunyinya :

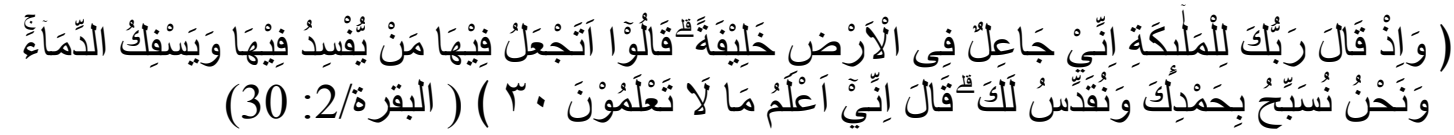

Artinya : "Dan (ingatlah) ketika Tuhanmu berfirman kepada para malaikat, "Aku hendak menjadikan khalifah di bumi." Mereka berkata, "Apakah Engkau hendak menjadikan orang yang merusak dan menumpahkan darah di sana, sedangkan kami bertasbih memuji-Mu dan menyucikan namaMu?" Dia berfirman, "Sungguh, Aku mengetahui apa yang tidak kamu ketahui." (Al-Baqarah/2:30)

Dengan demikian, hakikat penciptaan tersebut selayaknya bisa membuat manusia sadar bahwa sebagai makhluq yang diciptakan paling sempurna diantara makhluq Allah yang lain bisa mempertebal keimanan dalam menyembah Allah diantaranya dalam penerapan sifat Qonaah dalam membatasi hawa nafsu duniawi.

\section{Pengertian Qana'ah}

Menurut bahasa Qana'ah artinya menerima apa adanya atau tidak serakah ${ }^{1}$. Sedangkan secara istilah ialah satu akhlak mulia yaitu menerima rezeki apa adanya dan menganggapnya sebagai kekayaan yang membuat mereka terjaga statusnya dari memintaminta kepada orang. ${ }^{2}$ Dari pengertian diatas dapat disimpulkan bahwa orang yang memiliki sifat Qana'ah adalah orang yang merasa puas dengan apa yang telah ia miliki, dan menerima apapun anugerah yang telah diberikan oleh Allah kepadanya baik banyak ataupun sedikit.

Dijelaskan juga bahwa qana'ah adalah sikap tenang dalam menghadapi hilangnya sesuatu yang ada. Muhammad bin Ali At Tirmidzi menegaskan bahwa : Qana'ah ialah kepuasan jiwa atas rezeki yang dilimpahkan kepadanya. Dikatakan pula qana'ah adalah

\footnotetext{
${ }^{1}$ Sudarsono, Etika Islam : Tentang Kenakalan Remaja, (Jakarta: Rineka Cipta, 2005), hlm 57.

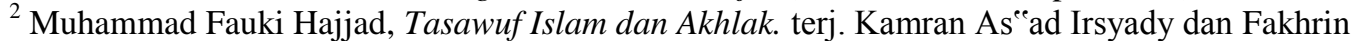
Ghozali, (Jakarta: Amzah, 2011), hlm 338-339.
} 


\section{Jurnal Asy-Syukriyyah}

menemukan kecukupan di dalam yang ada ditangan. ${ }^{3}$ Maksudnya tidak rakus dan menerima pemberian dari Allah SWT.

Pandangan lain dari Amin Syukur bahwa Qana'ah ialah menerimanya hati terhadap apa yang ada, walau sedikit, kemudian tidak lupa dibarengi dengan sikap aktif dan terus berusaha karena orang yang qana'ah akan menganggap cukup apa yang dipunya sebagai karunia dari Allah. ${ }^{4}$

Qana'ah ini mengajarkan kepada manusia untuk menerima apa yang ada, dan bukan mencari apa yang tidak ada. ${ }^{5}$ Dalam pelaksananya Qana'ah adalah satu kesatuan dengan Zuhud, karena zuhud manusia memandang dan memegang dunia bukan pada hatinya akan tetapi pada tanganya saja.

Kata Zuhud dilihat dari bahasa memiliki arti meninggalkan, tidak memperhatikan. Jadi Zuhud adalah sikap menghindari kesenangan duniawi untuk mencari bekal di akhirat dengan sebanyak-banyaknya. ${ }^{6}$ Jadi Zuhud bukan berarti seperti kependetaan meninggalkan keduniawian dan hanya berfokus kepada akherat saja, akan tetapi dalam mencari keduniawian sewajarnya dan tidak menghalalkan segala cara padahal melanggar batasbatas aturan agama, disebabkan akheratnyalah tujuan utamanya bukan dunia.

Qana'ah ialah logistik yang tak pernah habis, yang mana tidak seperti kehidupan yang pasti terkikis dan musnah, hiduplah dengan qana'ah, yaitu menerima apa yang ada, jangan tamak jangan mencari yang tidak ada. Kelak kau akan bahagia, terpuji dimata orang, dan mulia di mata tuhan. ${ }^{7}$

Dalam buku yang berjudul Kehidupan manusia di tengah-tengah alam materi, menjelaskan bahwa qana'ah ialah menerima apa yang ada atau menerima cukup pemberian

\footnotetext{
${ }^{3}$ Muhammad Husain Fadhullah, Islam dan Logika Kekuatan, terj. Afif Muhammad dan HLM Abdul Adhim, (Bandung: Anggota IKAPI, 1995), hlm 57.

${ }^{4}$ Amin Syukur, Sufi Healing : Terapi dengan Metode Tasawuf, (Jakarta : Penerbit Erlangga, 2012), hlm 62-63.

${ }^{5}$ Assayid Bakri Al Maliki, Merambah Jalan Shufi Menuju Surga Ilahi, (Bandung : Sinar Baru Algensindo, cet III, 2002), hlm 26.

${ }^{6}$ Ahmad Warson Munawwir, Kamus Al Munawwir Arab Indonesia Terlengkap,hlm 588.

${ }^{7}$ As Sayyid Bakri Al Makki, Merambah Jalan Shufi : Jalan Menuju Surga, (Bandung : Al gensindo, 1995), hlm 26.
} 


\section{Jurnal Asy-Syukriyyah}

dari Allah, tidak akan menggerutu tentang apa yang sudah diberikan, serta menerimanya dengan senang hati. Di dalam buku ini juga dijelaskan jangan sampai manusia hanya bermalas- malasan, tapi juga harus tetap menegakkan ikhtiar. Jika memang ikhtiar yang dilakukan kurang memuaskan tetaplah tenang dan jangan menggerutu karena orang yang qana ${ }^{e e} a h$ ialah orang yang tidak mudah terpengaruh oleh pasang surutnya keadaan dirinya. ${ }^{8}$ Seorang muslim pasti akan mengikuti segala sesuatu yang telah diperintahkan dalam AlQur'an maupun Hadits, yaitu selain diharuskan untuk berusaha, berdoa, tawakal, bersabar, bersyukur maka Qana'ah lah yang akan menyempurnakan usaha manusia tersebut untuk membatasi hawa nafsu duniawinya.

Qana'ah merupakan modal yang paling teguh untuk menghadapi kehidupan, karena dapat menimbulkan semangat dalam mencari rezeki, dengan tetap memantapkan pikiran, meneguhkan hati, bertawakal kepada Allah, mengharapkan pertolongannya, dan tidak putus asa ketika tidak berhasil atau impian yang diinginkan tidak terwujud ${ }^{9}$

Yang dimaksudukan qana ah disini ialah bukan hanya berpangku tangan dan pasrah dalam menerima keadaan, namun qanae ah yang dimaksudkan tersebut juga dapat difungsikan sebagai cara untuk menjaga kesederhanaan dari hati agar tetap dalam ketentraman, agar terhindar dari beberapa lenanya dunia, serta tidak berorientasi pada harta saja. Karena orang yang qana"eah telah memagar hartanya sekedar apa yang ada didalam tangannya dan tidak menjalar pikirannya kepada yang lain. ${ }^{10}$

Dari pendapat diatas dapat disimpulkan bahwa Qana'ah adalah sikap menerima pemberian yang telah dianugerahkan oleh Allah dan selalu mensyukuri berapapun yang dia dapatkan dengan cara mencukupkan dengan yang dipunya baik banyak ataupun sedikit atau dengan kata lain tidak diperbudak oleh dunia.

${ }^{8}$ Abdul Fatah, Kehidupan Manusia di Tengah-tengah Alam Materi, ( Jakarta : PT Rineka Cipta, 1995 ), hlm. 92 .

${ }^{9}$ Muhammad Rifa ${ }^{e} \mathrm{i}$ Subhi, Tasawuf Modern : Paradigma Alternatif Pendidikan Islam, (Pemalang : Alrif Manegement, 2012), hlm. 47.

${ }^{10}$ Hamka, Tasawuf Modern, hlm. 268. 


\section{Jurnal Asy-Syukriyyah}

\section{Qana'ah dalam Al-Qur'an dan Al-Hadits}

Allah telah berfirman dalam al-Qur'an dan diperkuat dalam Hadits diantaranya :

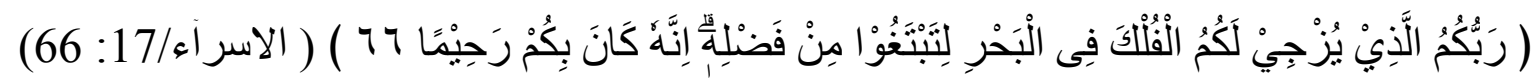

Artinya: " Tuhanmulah yang melayarkan kapal-kapal di lautan untukmu, agar kamu mencari karunia-Nya. Sungguh, Dia Maha Penyayang terhadapmu. (AlIsra'/17:66)

Dalam Tafsir Al-Azhar dijelaskan bahwa manusia diperintahkan agar tidak bermalas-malasan dan tidak berpangku tangan, mereka diperintahkan untuk mencari karunia-Nya yang tidak lain adalah untuk mencari rezeki yang telah dilimpahkan oleh Allah. ${ }^{11}$ Dan hal itu sesuai dengan pengertian qana'ah, menerimanya hati terhadap apa yang ada, walaupun sedikit, lalu tidak lupa disertai sikap aktif, serta terus berusaha. ${ }^{12} \mathrm{Hal}$ ini disebutkan dalam firman Allah SWT Surat Ibrahim ayat 7 yang bunyinya :

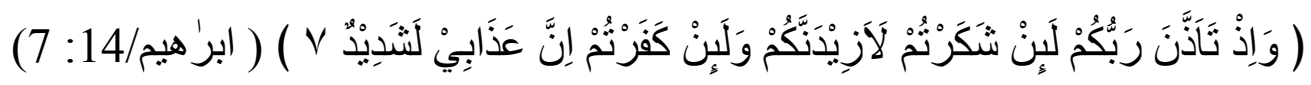

Artinya : "Dan (ingatlah) ketika Tuhanmu memaklumkan, "Sesungguhnya jika kamu bersyukur, niscaya Aku akan menambah (nikmat) kepadamu, tetapi jika kamu mengingkari (nikmat-Ku), maka pasti azab-Ku sangat berat." (Ibrahim/14:7)

Di dalam ayat Al Qur"ean di atas jika menjelaskan tentang munculnya sikap kufur sebagaimana yang tertera dalam buku Tafsir Al Azhar, kufur ialah sebuah sikap merasa tidak puas dengan nikmat yang telah diberikan dari Allah, dan selalu merasa kurang dengan apa yang sudah diberikan. ${ }^{13}$ Hal tersebut sangat tidak menggambarkan konsep dari qana'ah itu sendiri, yang mana qana'ah sendiri ialah menerima segala ketentuan Allah dengan ikhlas tanpa mengeluh sekalipun.

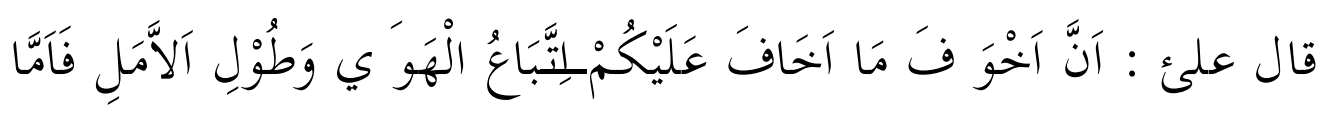

\footnotetext{
${ }^{11}$ Hamka, Tafsir Al Azhar, Jilid 5, (Jakrta : Gema Insani, 2015), hlm .311-312

${ }^{12}$ Amin Syukur, Sufi Healing, hlm 62-63.

${ }^{13}$ Hamka, Tafsir Al Azhar, Jilid 8, hlm 87-88.
} 


\section{Jurnal Asy-Syukriyyah}

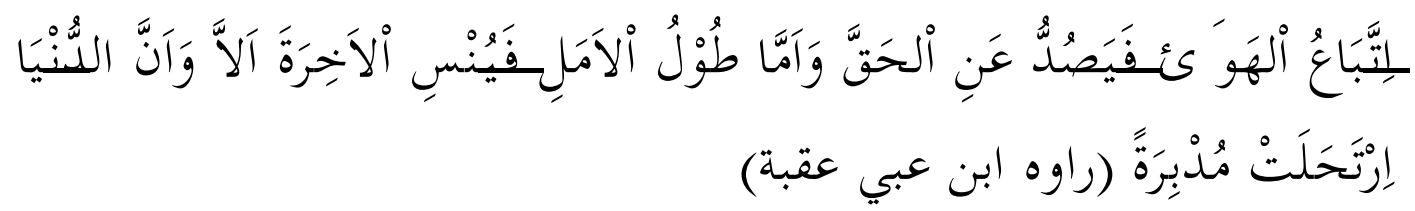

"Sesungguhnya yang paling aku khawatirkan terhadap kalian adalah menuruti hawa nafsu dan panjang angan-angan. Menuruti hawa nafsu akan menghalangi dari kebenaran, sedangkan panjang angan-angan akan membuat lupa akhirat, ketahuilah dunia itu berlalu sambil membelakangi." (H.R. Ibnu Abi Uqbah) ${ }^{14}$

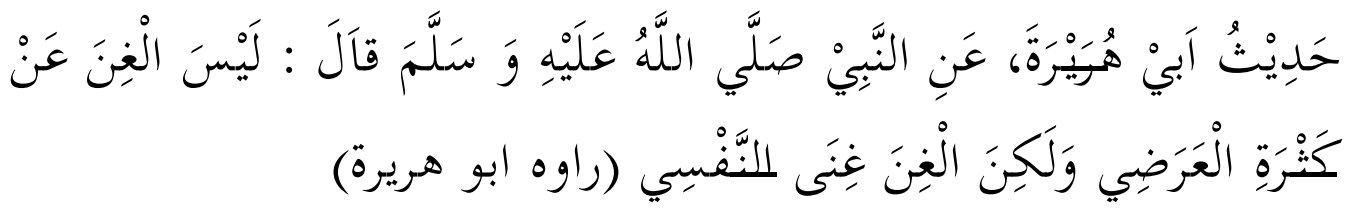

Bukanlah kaya itu dengan banyaknya harta, tetapi kaya itu adalah kaya jiwa. (H.R. Abu Hurairah). ${ }^{15}$

Dari penjelasan ayat dan juga hadits tersebut sudah jelas menerangkan bagaimana qana'ah itu, apa arti qana'ah, serta apa manfaat bagi manusia untuk menerapkan berqana'ah dalam kehidupan duniawi di zaman sekarang.

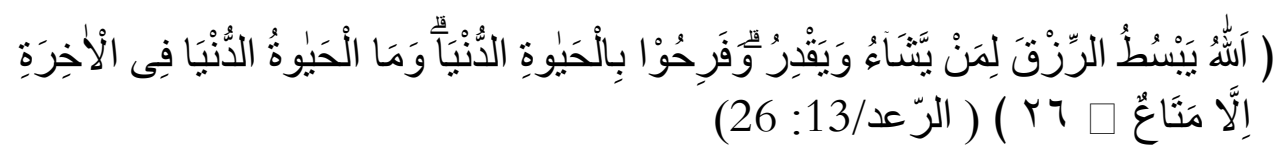

"Allah melapangkan rezeki bagi siapa yang Dia kehendaki dan membatasi (bagi siapa yang Dia kehendaki). Mereka bergembira dengan kehidupan dunia, padahal kehidupan dunia hanyalah kesenangan (yang sedikit) dibanding kehidupan akhirat. (Ar-Ra'd/13:26)

Manusia tidak mengetahui bahwa sesungguhnya kehidupan yang kekal ialah kehidupan di akhirat dan di sanalah nikmat yang sesungguhnya, maka dari alangkah baiknya manuisa yang telah dilenakan oleh gemerlapnya dunia mereka harusnya sadar bahwa hidup itu hanya sementara

${ }^{14} \mathrm{Al}$ Imam Al Hafizh Ibnu Hajar Al As Qalanni, Fathul Baari, hlm 25- .26

${ }^{15}$ Muhammad Fu"ead Abdul Baqi, Al Lu“luu wal Marjan Fima Ittafaqa „, Alaihi Asy Syaikhani Al Bukhari wa Muslim, terj. Arif Rahman Hakim, (Solo: Al Andalus, 2014), hlm 274. 


\section{Penerapan Sifat Qana'ah}

Dari berbagai pengertian diatas bagaimana cara penerapan sifat Qana'ah dapat dilihat pada lima konsep qana'ah yang telah dipaparkan oleh Hamka dalam bukunya yaitu Tasawuf Modern, yaitu :

1. Menerima dengan rela apa yang ada. Maksudnya sesuatu yang diberikan oleh Allah haruslah diterima dengan senang hati dan tidak mudah menggerutu, karena dalam qana ${ }^{e e}$ ah sendiri sikap rela (ridha) tertera dalamnya, yang selanjutnya juga ridha terbagi menjadi dua sebagaimana yang telah dikutip Amin Syukur dalam Ma ${ }^{e e}$ luf meyatakan bahwa rela (ridha) yang pertama adalah ridha Allah terhadap hambanya, dan ridha hamba terhadap Allah. ${ }^{16}$

2. Memohon tambahan yang sepantasnya kepada Allah yang dibarengi dengan usaha. Berupaya untuk terus positif thingking alias khusnudzan tentang segala yang sudah digariskan oleh Allah, karena Allah akan menghargai usaha dan bagaimana hambanya bersyukur, serta Allah pastilah akan memberikan balasan atas usaha dan rasa syukur pada hambanya,.

3. Menerima dengan sabar akan ketentuan Allah. Dengan sabar dimaksudkan untuk tetap kuat, tidak gelisah serta cemas akan takdir yang telah Allah janjikan, dari keteguhan dan keyakinan itulah, segala kegelisahan bisa sirna.

4. Bertawakal kepada Allah. Yaitu percaya bahwa segala ketetapanya pasti akan dipenuhi oleh-Nya, dan tak ada kata ragu dalam diri ini, karena tawakal adalah akibat dari orang yang beriman. ${ }^{17}$

5. Tidak tertarik oleh tipu dunia. Pada bagian ini menjelaskan bahwa dalam qana "ah terdapat juga unsur-unsur zuhud.

\footnotetext{
${ }^{16}$ Amin Syukur, Sufi Healing : Terapi dengan Metode Tasawuf, ( Jakarta : Penerbit Erlangga, 2012), hlm 63.

${ }^{17}$ Hamka, Tafsir Al azhar, Jilid 2, ( Jakarta : Gema Insani, 2015 ), hlm 109.
} 


\section{Mengendalikan Hawa Nafsu Duniawi}

Hawa sering digunakan untuk mengungkap kecenderungan nafsu buruk manusia. Al-Syi'bi mengatakan bahwa al-hawa adalah sesuatu yang kalau dituruti akan merendahkan pelakunya. ${ }^{18}$ Quraish Shihab mengemukakan pandangannya bahwa seseorang yang mengikuti hawa nafsu sama saja orang tersebut tergesa-gesa dalam mengambil keputusan. ${ }^{19}$

Salah satu unsur penting yang terdapat dalam diri manusia adalah hawa nafsu karena semua manusia memilikinya, sedangkan tabiat nafsu adalah mengajak manusia pada kenikmatan dunia kecuali nafsu yang dirahmati Allah,seperti halnya yang diungkapkan dalam Q.S. Yūsuf : 53

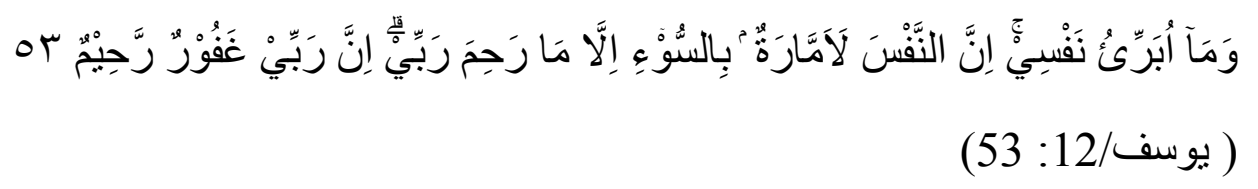

"Dan aku tidak (menyatakan) diriku bebas (dari kesalahan), karena sesungguhnya nafsu itu selalu mendorong kepada kejahatan, kecuali (nafsu) yang diberi rahmat oleh Tuhanku. Sesungguhnya Tuhanku Maha Pengampun, Maha Penyayang. (Yusuf/12:53)

Pada ayat di atas menjelaskan bahwa tidak ada yang mendorong seseorang melakukan sesuatu kecuali hawa nafsu dan syahwat. Karena pada dasarnya nafsu manusia selalu mendorong jiwanya untuk melakukan keburukan, kecuali jiwa yang dirahmati Allah dan dipelihara dari kedurhakaan seperti halnya Nabi Yusuf yang selalu berusaha mengendalikan nafsunya dengan menjalankan ketaatan kepada Allah. ${ }^{20}$

Segala sesuatu yang dihadapi oleh seorang hamba di dunia ini merupakan salah satu dari dua hal yaitu:sesuatu yang sesuai dengan hawa nafsu dan keinginannya ataupun sebaliknya. Perkara yang sesuai dengan keinginannya seperti kesehatan, kehormatan, dan harta. Sedangkan perkara yang tidak sesuai dengan keinginannya seperti datangnya 92. 132-133.

${ }^{18}$ Dahlan Tamrin, Tasawuf Irfani: Tutup Nasut Buka Lahut (Malang: UIN Maliki Press, 2010), hlm

${ }^{19}$ M. Quraish Shihab, Tafsir Al-Misbah: Pesan, Kesan dan Keserasian Al-Qur'an. . . Vol. 6, hlm

${ }^{20}$ M. Quraish Shihab, Tafsir Al-Misbah: Pesan, Kesan dan Keserasian al-Qur'an. . Vol. 6, hlm 482. 


\section{Jurnal Asy-Syukriyyah}

musibah. $^{21}$

Manusia yang bersungguh-sungguh mengendalikan hawa nafsu duniawi niscaya akan dimudahkan oeh Allah untuk meninggalkan perbuatan dosa dan maksiat. Seperti yang telah di firmankan Allah dalam Al-Qur'an Surat Al Ankabut ayat 69 :

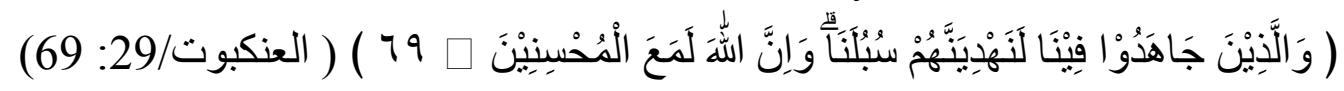

"Dan orang-orang yang berjihad untuk (mencari keridaan) Kami, Kami akan tunjukkan kepada mereka jalan-jalan Kami. Dan sungguh, Allah beserta orang-orang yang berbuat baik. (Al-'Ankabut/29:69)

Dan Allah juga berfirman dalam Al-Qur'an Surat Maryam ayat 76 :

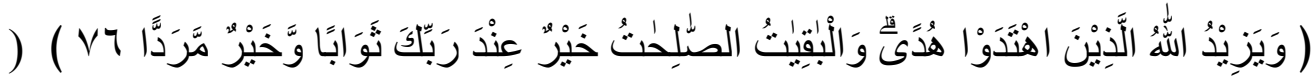

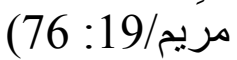

"Dan Allah akan menambah petunjuk kepada mereka yang telah mendapat petunjuk. Dan amal kebajikan yang kekal itu lebih baik pahalanya di sisi Tuhanmu dan lebih baik kesudahannya. (Maryam/19:76)

Dari ayat diatas sudah sangat jelas bahwa apabila manusia bersungguh-sungguh dalam melawan godaan setan atau nafsu duniawi maka Allah akan memudahkanya dalam mendapatkan hidayah jalan petunjuk. Sebaliknya apabila manusia menyerah terhadap hawa nafsunya maka dia akan lemah serta melupakan perintah larangan Allah, dan niscaya akan menjadi tawanan dari hawa nafsunya tersebut, sehingga perbuatan dosa dan maksiatpun akan dilakukan hanya untuk melaksanakan perintah dari hawa nafsu duniawinya, contoh berani berbohong, menipu, menghalalkan segala cara dan tidak bersyukur terhadap apa yang telah didapatkan dan dimilikinya.

${ }^{21}$ bnu Qayyim al-Jauziyyah, Tazkiyatun Nafs: Konsep Penyucian Jiwa Menurut Para Salaf, terj. Imtihan Asy-Syafi'i(Solo: Pustaka Arafah, 2004), hlm 105 


\section{Jurnal Asy-Syukriyyah}

\section{F. KESIMPULAN}

Pengaruh hawa nafsu sangat kuat pada diri manusia, semakin sering melakukan intervensi terhadap hati yang murni maka akan semakin mudah mencampuradukkan hati dengan dorongan nafsu yang bersifat duniawi. Dengan demikian, qanaah yang telah disebutkan dalam Al-Qur'an maupun Hadits adalah salah satu cara mencegah dalam mengendalikan hawa nafsu duniawi untuk membentengi diri manusia khususnya bagi manusia yang selalu kurang dan tidak bersyukur atas apa-apa yang telah Allah anugerahkan kepadanya. 


\section{Jurnal Asy-Syukriyyah}

\section{DAFTAR PUSTAKA}

Abdul Fatah, Kehidupan Manusia di Tengah-tengah Alam Materi, (Jakarta : PT Rineka Cipta, 1995),

Ahmad Warson Munawwir, Kamus Al Munawwir Arab Indonesia Terlengkap,

Al Imam Al Hafizh Ibnu Hajar Al As Qalanni, Fathul Baari,

Amin Syukur, Sufi Healing : Terapi dengan Metode Tasawuf, (Jakarta : Penerbit Erlangga, 2012),

Assayid Bakri Al Maliki, Merambah Jalan Shufi Menuju Surga Ilahi, (Bandung : Sinar Baru Algensindo, cet III, 2002),

As Sayyid Bakri Al Makki, Merambah Jalan Shufi : Jalan Menuju Surga, (Bandung : Al gensindo, 1995),

Dahlan Tamrin, Tasawuf Irfani: Tutup Nasut Buka Lahut (Malang: UIN Maliki Press, 2010),

Departemen Agama Republik Indonesia, Al Qur"an dan Terjemahannya,

Hamka,Tasawuf Modern, (Jakarta : Gema Insani, 2015),

Hamka, Tafsir Al Azhar, Jilid 5, (Jakarta : Gema Insani, 2015),

Ibnu Qayyim al-Jauziyyah, Tazkiyatun Nafs: Konsep Penyucian Jiwa Menurut Para Salaf, terj. Imtihan Asy-Syafi'I, (Solo: Pustaka Arafah, 2004),

Kementerian Agama RI, Al Qur"an dan Tafsirnya (Edisi yang Disempurnakan), (Jakarta : Widya Cahaya, 2011),

Muhammad Fauki Hajjad, Tasawuf Islam dan Akhlak. terj. Kamran Aseead Irsyady danFakhrin Ghozali, (Jakarta: Amzah, 2011),

Muhammad Husain Fadhullah, Islam dan Logika Kekuatan, terj. Afif Muhammad dan H. Abdul Adhim, (Bandung: Anggota IKAPI, 1995),

Muhammad Rifaei Subhi, Tasawuf Modern : Paradigma Alternatif Pendidikan Islam, (Pemalang : Alrif Manegement, 2012), 


\section{Jurnal Asy-Syukriyyah}

Muhammad Fu"ead Abdul Baqi, Al Lu“luu wal Marjan Fima Ittafaqa „Alaihi Asy Syaikhani Al Bukhari wa Muslim, terj. Arif Rahman Hakim, (Solo: Al Andalus, 2014),

M. Quraish Shihab, Tafsir Al-Misbah: Pesan, Kesan dan Keserasian Al-Qur'an. (Jakarta:Lentera Hati, 2007).Vol. 6,

Sudarsono, Etika Islam : Tentang Kenakalan Remaja, (Jakarta: Rineka Cipta, 2005), 